\title{
SER COMO FIM IMANENTE: A ÉTICA DA RESPONSABILIDADE DE HANS JONAS
}

Being as an immanent end: Hans Jonas' ethic of responsibility

Gabriel Prado Rodrigues

Graduando em Filosofia/UFRJ

\begin{abstract}
RESUMO: Minha pesquisa tem como foco a elucidação dos pontos principais do sistema teórico elaborado pelo filósofo alemão Hans Jonas, em especial no que tange à sua ética. Para Jonas, o advento da técnica moderna modificou em grande medida a forma como os seres humanos interagem com a natureza e consigo mesmos. A humanidade não apenas dispõe de novos meios para realizar ações sobre o planeta como lhe foge, por vezes, o controle e a capacidade para prever os resultados de seus empreendimentos. Estes e outros aspectos de nossa civilização tecnocientífica suscitam problemas cujas soluções não foram pensadas por éticas tradicionais o que, para Jonas, indica a necessidade do desenvolvimento um novo sistema ético centrado no princípio responsabilidade, de fundamento ontológico, para dar conta do risco que correm seres humanos e não humanos em virtude das novas dimensões espaçotemporais das ações do homem. Nesse sentido, a ética jonasiana é também uma ética do futuro, uma vez que busca englobar ainda ações da técnica moderna cujas consequências negativas talvez levem muito tempo para aparecer. Tendo como principal fonte de pesquisa o livro Princípio Responsabilidade, de Jonas, procurei apontar e esclarecer conceitos elementares de seu pensamento, além de brevemente traçar seu lugar em relação a algumas tendências filosóficas também questionadoras do papel da ciência e da tecnologia modernas na sociedade.
\end{abstract}

PALAVRAS-CHAVE: Hans Jonas; ética; responsabilidade.

ABSTRACT: My research focuses on the elucidation of the main points of the theoretical system elaborated by the German philosopher Hans Jonas, especially with regard to his ethics. For Jonas, the advent of modern technology has greatly changed the way humans interact with nature and with themselves. Humanity not only has new means to carry out actions on the planet but sometimes it lacks the control and the ability to predict the results of its ventures. These and other aspects of our technoscientific civilization give rise to problems whose solutions were not proposed by traditional ethics. Jonas sought to develop a new ethical system centered on the ontological principle of responsibility to account for the risk that human and non-human beings have in virtue of the new spatio-temporal dimensions of human actions. In this sense, Jonasian 
ethics is also aimed at the future, since it seeks to include actions of modern technique whose negative consequences may take a long time to appear. Having as main research source the book The Imperative of Responsibility, I tried to point out and clarify elementary concepts of his thought, as well as to briefly trace his place in relation to some philosophical tendencies that also question the role of modern science and technology in society.

KEYWORDS: Hans Jonas; ethics; responsibility.

\section{INTRODUÇÃO}

Hans Jonas (1903-1993) propõe o resgate de finalidades naturais imanentes como base para a fundamentação do dever do homem em relação ao mundo e seus habitantes. Em $O$ Princípio Responsabilidade, Jonas trava debate com inclinação teórica cientificista de alguns saberes de sua época, marcada pela influência do positivismo comteano disseminado ao longo do século XIX (DARTIGUES, 1992). De acordo com o positivismo, explicações científicas objetivas sobre a realidade são os paradigmas de todo conhecimento válido, de modo que "somente são reais os conhecimentos que repousam sobre fatos observados" (COMTE, 1973, p.11).O método das ciências naturais, renovado pela Revolução Científica que deu origem à ciência moderna no século XVII, ameaçaria assim ser estendido a outros campos, comprometendo o estudo de áreas como a Ética, cujos postulados não seriam verificáveis pela simples observação factual ou pela experimentação empírica controlada. Muitos pensadores identificaram as complicações derivadas da noção de ciência proposta pelo positivismo e procuraram criticá-la.

Por exemplo, Max Weber se refere à ciência e à religião ocidentais como instrumentos de um "desencantamento do mundo", isto é, do processo pelo qual fenômenos da realidade passariam a ser explicados de forma gradualmente menos mística e cada vez mais mecânica, desprovida de sentido próprio ${ }^{1}$. Também Edmund Husserl afirma que a pretensão de redução do conhecimento como um todo ao que pode ser produzido pela ciência empírica constitui o 'objetivismo', sob o qual o acesso da ciência ao real seria entendido como puro e totalmente livre de elementos subjetivos. Confunde-se assim a realidade com sua representação matematizada, com uma "veste de ideias" (HUSSERL, 1976, p.60). Cumpre dizer que o objetivo de tais críticas não foi eliminar a ciência como modo de verificação e produção de conhecimento, mas expor suas limitações quando tenta propor modelos totais de descrição do mundo. Isto equivale a

${ }^{1}$ Cf. SHULL, K.K. Is the Magic Gone? Weber's "Disenchantment of the World" and its Implications for Art in Today's World. Anamesa, New York, v.3, i. 2, p.61, fall. 2005. 
afirmar que o método científico é eficaz quando busca o conhecimento de objetos e a enunciação de suas relações através de leis, mas que não consegue abarcar todos os aspectos do real.

$\mathrm{Na}$ esteira desses pensamentos, Hans Jonas busca problematizar um dos principais frutos desta tendência cientificista: a técnica moderna. Para Jonas, a técnica moderna, pela primeira vez na história da humanidade, coloca em risco a existência da espécie humana como um todo assim como da natureza orgânica da qual faz parte. Isso ocorre porque os mecanismos e o dinamismo das criações tecnológicas começam a ultrapassar em grande medida o poder de previsão e de controle do homem sobre suas invenções. Para Jonas, é necessário que a ciência, separada da filosofia a partir da modernidade e compreendida desde então como domínio do empírico e do experimental, também seja pensada à luz da ética. É imperativo questionar a distinção essencial entre dever e ser pressuposta pela ciência, que parece recusar "qualquer direito teórico de pensar a natureza como algo que devamos respeitar - uma vez que ela a reduziu à indiferença da necessidade e do acaso, despindo-a de toda dignidade de fins." (JONAS, 2006, p.43)

Nesse ponto, Jonas coloca uma questão não levantada por filosofias morais tradicionais: o risco da destruição total do mundo e da impossibilidade das gerações futura sem virtude de ações humanas irrefletidas e a indispensabilidade da criação de um novo sistema ético com a finalidade de impedir a aniquilação do Ser. A Ética deve adentrar a esfera antes eticamente neutra da techne, isto é, da relação do ser humano com a "natureza" entendida como tudo que não é humano ou sua criação.

\section{HEIDEGGER E A TÉCNICA MODERNA}

Jonas foi profundamente influenciado pela obra de Martin Heidegger, de quem, não por acaso, foi aluno. A filosofia heideggeriana se funda no que Heidegger denomina "diferença ontológica", isto é, na distinção entre os conceitos de "ser" e de "ente". Para ele, ente "é tudo de que falamos dessa ou daquela maneira, ente é também o que e como nós mesmos somos" (HEIDEGGER, 2006, p.42), é o que designamos quando afirmamos que algo "é". Em suma, qualquer coisa no campo da experiência humana é um ente, um animal, uma planta, um pensamento e até mesmo nós, entes que investigam os entes em geral (ANDRADE, 1982). O ser, por sua vez, é "o que determina o ente como ente, o em vista de que o ente já está sempre sendo compreendido, em qualquer discussão" (Ibidem, p.41). Para Heidegger, o ser é aquilo que é sempre de um ente (Ibidem, p.77), que se desvela e se vela sempre a partir dos entes, mas nunca é, ele próprio, desvelado por completo. Ele se oculta e se mostra segundo modos de ser dos entes em virtude da natureza temporal da compreensão. 
O ponto de partida da concepção heideggeriana é a crítica a toda a história da metafísica ocidental como dimensão do esquecimento do ser desde Platão e Aristóteles até a Lógica de Hegel (Ibidem, p.37). Segundo Heidegger, o ser, a partir da tradição platônica, foi considerado de maneira "essencialista", a metafísica procurou pensar o ser enquanto ser, e não como modo de ser dos entes. O âmbito do "aparecer", no qual os entes se mostram a partir de si mesmos, foi ocultado pelo simples questionamento dos entes e não do ser. A abordagem essencialista tornouse dominante no campo da própria ciência moderna, que encara os entes já significados dentro das regras de seu próprio sistema.

Tal reflexão é relevante para entender o pensamento de Jonas pois Heidegger coloca, como ente privilegiado a partir do qual é possível o questionamento do ser enquanto domínio do aparecer, o que ele chama, em alemão, de Dasein. Dasein é nada mais que o ente humano, aquele capaz de compreender os modos de ser próprios dos entes e de questioná-los. Sua única determinação consiste em ser sempre abertura para modos possíveis de ser. Ele se diferencia dos outros entes, pois é o único que se dá conta de si mesmo no mundo e assim aparece para si, participa do desvelar do ser dos entes. É a partir do ente humano que se tem início o questionamento do sentido do ser. Heidegger parte disso quando diz que uma das possíveis formas de desvelamento é a técnica moderna (HEIDEGGER, 2002, p.18). Ao questionar a essência desse modo de desvelamento do ser, Heidegger conclui que ele explora os entes, desencobre (ou desvela) modos de ser de maneira violenta, exploratória, forçando a natureza a tomar formas que objetivam a satisfação de necessidades humanas. Exemplos disso são jazidas de minérios ou usinas hidrelétricas (Ibidem, p.20), modos que jamais viriam a ser naturalmente, sem a exploração humana. O desvelar do ser dos entes por eles mesmos é substituído pelo simples desvelamento de todos como energia a ser armazenada e subsequentemente consumida pela sociedade. A técnica moderna se concretizaria, assim, como a forma acabada do esquecimento do ser iniciado na metafísica platônica, como domínio da representação e da objetividade científica que se daria a partir do engessamento em um modo de ser técnico.

Jonas, como Heidegger, aponta também que a técnica em suas dimensões modernas instrumentaliza a relação entre o ser humano e a natureza. Pela primazia do modo técnico de desvelamento, segundo o qual tudo é meio e instrumento para algo, a relação do ser humano com a realidade como abertura para possibilidades seria colocada em risco. Nesse sentido, o questionamento da técnica moderna não é, em primeiro lugar, meramente relativo ao campo da prática em oposição ao da teoria:

O processo científico mesmo se desenvolve em inter-relação com o tecnológico, e isto no sentido intimamente mais vital: para alcançar seus próprios objetivos teóricos, a ciência necessita uma tecnologia cada vez mais 
refinada e fisicamente forte como ferramenta que se produz a si mesma, ou seja, que cabe à tecnologia. [...] Desse modo, o aparato é comum ao reino teórico e prático; ou seja, tanto a tecnologia infiltra-se na ciência quanto a ciência na tecnologia. Em resumo: existe entre elas uma mútua relação de feedback que as mantém em movimento; cada uma necessita e impulsiona a outra. (JONAS, 2013, p.30)

Técnica e ciência se tornam imbricadas em relação circular de mútua sustentação. A análise da técnica moderna, para além do exame de procedimentos alicerçados em teorias isoladas, deve também se estender às relações entre teoria e prática. Isso abre um novo plano de investigação em que é possível associar o surgimento de técnicas recentes a partir de relações mais antigas entre desenvolvimentos teóricos e suas respectivas práticas. Heidegger, por exemplo, sugere que o modo de desvelamento da técnica moderna já estava presente no gênero de representação da ciência moderna, antes mesmo do surgimento das tecnologias modernas enquanto atividades concretas:

O homem na idade da técnica vê-se desafiado, de forma especialmente incisiva, a comprometer-se com o desencobrimento [ou desvelamento]. Em primeiro lugar, ele lida com a natureza, enquanto o principal reservatório das reservas de energia. Em consequência, o comportamento dis-positivo do homem mostrase, inicialmente, no aparecimento das ciências modernas da natureza. O seu modo de representação encara a natureza como um sistema operativo e calculável de forças. A física moderna não é experimental por usar, nas investigações da natureza, aparelhos e ferramentas. Ao contrário: porque, já na condição de pura teoria, a física leva a natureza a ex-por-se, como um sistema de forças que se pode operar previamente, é que se dis-põe do experimento para testar, se a natureza confirma tal condição e o modo em que o faz. (HEIDEGGER, 2002, p.24)

O termo "dis-por" indica o modo de desvelar da técnica moderna, em que

dá-se com propriedade aquele desencobrimento em cuja consonância $\mathrm{O}$ trabalho da técnica moderna des-encobre o real, como dis-ponibilidade. Por isso a técnica não se reduz apenas a uma atividade humana e muito menos a um simples meio desta atividade. A determinação da técnica meramente instrumental e antropológica se torna, em princípio, de menos importância; ajuntar-lhe, depois, uma explicação metafísica tampouco seria capaz de completá-la. (idem)

Sob ótica heideggeriana, a técnica se apresenta como a própria forma de vir a ser dos entes, de maneira que a realidade como tal é apreendida através da ótica tecnocientífica. Ora, a crítica ao positivismo e à sua influência então torna-se indispensável, dado que, para além do plano epistemológico, a generalização da perspectiva instrumental e minimalista da ciência não influencia apenas novos saberes, como também cada aspecto da vida humana. A realidade se 
desvela como "disponível", isto é, como dotada de único sentido: o de possível instrumento para empreendimentos tecnocientíficos em geral.

Nesse sentido, a ética jonasiana foca em dois pontos bastante amplos. Em primeiro lugar, na questão existencial da responsabilidade como modo de ser do homem, isto é, como sentido possível de ser da realidade. A possibilidade da responsabilidade deve ser preservada pelo trabalho fenomenológico de desvelamento deste modo de ser humano, que se funda no próprio aparecer imanente da realidade em suas diferentes formas e finalidades. Este aspecto da teoria jonasiana será melhor explicado adiante. Em segundo lugar, além do resgate dos fins imanentes intrínsecos à natureza, Jonas põe em questão o risco do não-Ser como possível consequência do advento da técnica moderna. Ele reivindica a necessidade do desenvolvimento de uma ética em que a "responsabilidade" em relação à natureza seja um apelo ao dever humano fundado em bases ontológicas.

\section{A NECESSIDADE DE UMA ÉTICA DO FUTURO}

A fundamentação da ética de Jonas começa pelo questionamento de sua necessidade. $\mathrm{O}$ autor preocupa-se com aspecto deixado de lado por éticas anteriores: "a crítica vulnerabilidade da natureza provocada pela intervenção técnica do homem" (JONAS, 2006, p.39). Segundo Jonas, nenhum pensador anterior preparou uma ética para lidar com tal questão em larga escala, isto é, considerando o empreendimento técnico como possível veículo para a extinção de toda a biosfera terrestre. Isto não decorre de suposta "negligência" de teóricos da moral anteriores, mas da impossibilidade de previsão das modificações do agir humano ocasionadas pelo desenvolvimento da técnica e de suas consequências.

Mais especificamente, creio que certas transformações em nossas capacidades acarretaram uma mudança na natureza do agir humano. E, já que a ética tem a ver com o agir, a consequência lógica disso é que a natureza modificada do agir humano também impõe uma modificação na ética. E isso não somente no sentido de que os novos objetos do agir ampliaram materialmente o domínio dos casos aos quais se devem aplicar as regras de conduta em vigor, mas em muitas das nossas ações descortinou uma dimensão inteiramente nova de significado ético, não prevista nas perspectivas e nos cânones da ética tradicional.

As novas faculdades que tenho em mente são, evidentemente, as da técnica moderna. Portanto, minha primeira questão é a respeito do modo como essa técnica afeta a natureza do nosso agir, até que ponto ela torna o agir sob seu domínio algo diferente do que existiu ao longo dos tempos. (Ibidem, p.29)

Como aponta Jonas, a modernidade assinala o ponto decisivo de ruptura com um cenário histórico em que a relação do ser humano com a natureza era notavelmente distinta. Havia uma 
diferença clara entre o âmbito artificial da invenção humana, como a cidade, marcada por permanência que não se sustentava a longo prazo, e o mundo natural, que incluía o ser humano e se caracterizava por sua sustentação inexorável. Em tempos pré-modernos,

sua vida [do ser humano] desenvolveu-se entre o que permanecia e o que mudava: o que permanecia era a natureza, o que mudava eram suas próprias obras. A maior dessas obras era a cidade, à qual ele podia emprestar um certo grau de permanência por meios que inventava e aos quais se dispunha a obedecer. Mas essa permanência, artificialmente produzida, não oferecia nenhuma garantia de longo prazo. [...] Estados erguem-se e caem, dominações vêm e vão, famílias prosperam e degeneram - nenhuma mudança é para durar. No final, na compensação recíproca de todos os desvios passageiros, a condição do homem permanece como sempre foi. (Ibidem, p.33)

Em meio à natureza, o homem erigiu a cidade como plano artificialmente circunscrito de suas invenções e de sua segurança, em oposição ao mundo natural, por vezes ameaçador nas figuras de criaturas desconhecidas e catástrofes naturais. A natureza "não era objeto da responsabilidade - ela cuidava de si mesma e, com a persuasão e a insistência necessárias, também tomava conta do homem: diante dela eram úteis a inteligência e a inventividade, não a ética" (Ibidem, pp. 33-34). Para Jonas, esta discriminação entre os âmbitos natural e artificial não apenas era nitidamente delineada em tempos pré-modernos, como suas características eram também distintas: a natureza seria grandiosa, autossuficiente e perene, as criações humanas, engenhosas, porém marcadas pela limitação frente à imponência da ordem cósmica.

A fragilidade da natureza não teria sido ainda colocada como questão, de modo que "todo o trato com o mundo extra-humano, isto é, todo o domínio da techne (habilidade) era - à exceção da medicina - eticamente neutro, considerando-se tanto o objeto quanto o sujeito de tal agir”. (Ibidem, p.35) A “significação ética dizia respeito ao relacionamento direto de homem com homem, inclusive o de cada homem consigo mesmo [...]" (idem). À existência da natureza como tal não se apresentava risco algum. A ética, por sua vez, limitava-se a abarcar os indivíduos humanos e suas ações de curto horizonte espaçotemporal. As éticas anteriores foram eficientes nas análises dessas ações de reduzida abrangência e nas previsões de suas consequências imediatas. O agir técnico recente do homem, no entanto, faz com que a capacidade humana de influência na realidade ultrapasse amplamente o poder de previsão de seus efeitos. Seu poder causal se estende para além do que o conhecimento pode abarcar com exatidão, algo extremamente preocupante neste caso, dadas as dimensões da ameaça que se anuncia. Toda a natureza se apresenta como objeto sujeito a modificações humanas, de modo que o homem se torna, pela primeira vez na história, responsável pelo conjunto de ecossistemas terrestres em que 
se encontra assim como pelas futuras gerações humanas, as quais dependem de condições favoráveis em seu planeta para existirem.

Jonas busca um novo imperativo ético que dê conta dos problemas colocados pela nova forma de agir humana modulada pela técnica moderna. Ele se volta, primeiramente, para uma das mais célebres tentativas filosóficas de universalidade no caso da ética, o imperativo categórico, de Kant, que afirma: "Aja de modo que tu também possas querer que tua máxima se torne lei geral." (Ibidem, p.47) $\mathrm{O}$ enunciado kantiano traça os limites normativos do conjunto de ações que devem ser realizadas pelo sujeito racional: aquelas que o sujeito, através de sua vontade livre, pode conceber como possivelmente realizadas por todos os outros em circunstâncias similares. Jonas aponta que, no imperativo categórico,

a reflexão básica da moral não é propriamente moral, mas lógica: o "poder" ou "não poder" querer expressa autocompatibilidade ou incompatibilidade, e não aprovação ou desaprovação. Mas não existe nenhuma contradição em si na ideia de que a humanidade cesse de existir, e dessa forma também nenhuma contradição em si na ideia de que a felicidade das gerações presentes e seguintes possa ser paga com a infelicidade ou mesmo com a não existência de gerações pósteras [...]. (Idem)

O imperativo é legitimado pela compatibilidade lógica da universalização da ação em relação a todos os atores da comunidade expressa no “"poder' ou 'não poder' querer do sujeito autônomo. Caso o exercício geral de uma ação por todos os indivíduos implique em contradição, a ação não deve ser posta em prática. Para Jonas, o pressuposto moral kantiano é insuficiente para o propósito de sua ética, a saber, a garantia da existência humana e de suas gerações futuras. Não há contradição na ideia de que a humanidade cesse de existir, por exemplo, ou de que "a existência e a felicidade das gerações futuras seja paga com a infelicidade e mesmo com a eliminação parcial da presente.” (Idem) A universalização perde o valor de legitimação de que é dotada no imperativo kantiano quando considerada do ponto de vista de Jonas, já que, no caso deste último, é colocada em risco a existência da própria comunidade de atores morais em que se daria a universalização.

Jonas propõe outro imperativo: "Aja de modo a que os efeitos da tua ação sejam compatíveis com a permanência de uma autêntica vida humana sobre a Terra." (Idem) A universalização kantiana é caracterizada por Jonas como "hipotética, isto é, a transferência meramente lógica do 'eu' individual para um 'todos imaginário', sem conexão causal com ele ('se cada um fizesse assim')" (Ibidem, p.49) ${ }^{2}$.No caso do imperativo categórico, "o princípio não é

${ }^{2} \mathrm{O}$ estatuto de "hipotética" atribuído por Jonas à universalização do imperativo categórico tem por objetivo a crítica ao modelo lógico a partir do qual se desdobra o imperativo, considerado insuficiente pelo filósofo. $\mathrm{O}$ termo não 
aquele da responsabilidade objetiva, e sim o da constituição objetiva de minha autodeterminação" (ibidem, pp. 48-49). O imperativo jonasiano, em contraste com o formalismo de Kant, concentra-se nas possíveis consequências diretas das ações, sem restrição ao suposto horizonte da autonomia do sujeito manifesta no "poder querer". Neste caso, "as ações do todo coletivo assumem a característica de universalidade na medida real de sua eficácia. Elas ‘totalizam’ a si próprias na progressão de seu impulso, desembocando forçosamente na configuração universal do estado das coisas." (Ibidem, p.49)

Ora, o conceito de liberdade kantiano se segue de sua preocupação em salvaguardar a possibilidade de autodeterminação racional do sujeito frente às concepções deterministas de filósofos de seu tempo, em especial as de David Hume. Para tanto, Kant precisava garantir em sua teoria um lugar para a autonomia subjetiva que não se furtasse ao mecanicismo vigente na modernidade. Jonas, por outro lado, busca fundamentar a garantia de que ações humanas não coloquem em risco a totalidade do planeta e a existência atual e futura de seus habitantes. $\mathrm{O}$ esforço jonasiano não deve ser confundido com a tentativa de estabelecimento de proposições éticas absolutas, inalteráveis com o tempo, mas de ética que inclua em seu escopo a existência de futuras gerações colocadas em risco por práticas realizadas no presente. Daí o enfoque do imperativo de Jonas nos "efeitos de sua ação", para além da mera garantia de autodeterminação do agente moral.

\section{FUNDAMENTAÇÃO ONTOLÓGICA}

Para Jonas, a distinção entre ser e dever pressuposta por "nosso tempo" é equivocada e constitui um dogma: ode que não há verdade metafísica (Ibidem, p.95). Jonas observa que o minimalismo materialista - que postula o ser como separado do dever - pressupõe também uma metafísica:

enquanto não tiver sido demonstrado que a ciência esgota integralmente o conceito de saber não terá sido dada a última palavra sobre a possibilidade da metafísica. Mas, mesmo que assim fosse, admitir que essa contestação não constituiria uma objeção particular contra a ética que buscamos, pois em qualquer outra ética, mesmo naquela mais utilitária, mais eudemonista e mais imanente, também se esconde implicitamente uma metafísica (o 'materialismo', por exemplo, seria uma). Portanto, nenhuma delas apresentaria qualquer vantagem em relação à nossa ética. O que há de particular em nosso caso é apenas o fato de que a metafísica nele presente não pode permanecer oculta, tendo de vir à luz [...]. Pois se também a tese negativa a respeito do "ser e dever" implica uma tese metafísica, o seu defensor pode se abandonar à

deve ser confundido com uma indicação da tradicional distinção kantiana entre imperativo categórico e imperativo hipotético. 
ignorância metafísica partilhada universalmente e refugiar-se na suposta superioridade metodológica da suposição mínima, isto é, da negação sobre a afirmação [da tese de que o dever e o ser são distintos]. Esse refúgio é negado à afirmação, e seu defensor deve se apresentar, senão uma prova, então ao menos um argumento ontológico racional para a sua suposição mais exigente. Portanto, ele necessita do ensaio metafísico, recurso do qual pode se poupar o "minimalista", invocando Ockham. (Ibidem, p.96)

O abandono da metafísica em favor da ciência é qualificado como arbitrário, uma vez que ambas têm como fundo uma concepção positiva de realidade (o que Jonas parece considerar equivalente à noção de metafísica entendida como estudo "do que é"). O mesmo vale para éticas imanentes em geral. A separação entre ser e dever apenas dificulta a tarefa do teórico que busca fundar metafisicamente suas suposições, o qual se vê obrigado a desenvolver um sistema que efetue a ligação entre o que é e o que deve ser. Ele necessita "ao menos de um argumento ontológico racional para a sua suposição mais exigente".

No caso do defensor da distinção dever/ser, basta que ele se refugie na "superioridade ontológica da suposição mínima" e invoque "Ockham”. Jonas faz aqui alusão ao conhecido princípio da parcimônia ou "navalha de Ockham", derivado da obra do filósofo medieval Guilherme de Ockham. O princípio, em sentido metafísico, postula "que devemos acreditar no menor número possível de objetos. Como princípio metodológico, a 'navalha de Ockham' diznos que qualquer explicação deve apelar ao menor número possível de fatos"' (BRANQUINHO, MURCHO e GOMES, 2006, p.536). A navalha, neste caso, é apontada por Jonas como simples instrumento de direcionamento do ônus da prova para o metafísico, que se vê forçado à incursão na ontologia da qual se livra o materialista.

Jonas nega o caráter supostamente ilusório da finalidade e a pensa como bem em si. Ela existe na natureza à medida que esta segue fins, como, por exemplo, a própria vida, que é veículo para a afirmação do Ser sobre o não-ser.

Em cada finalidade o Ser declara-se a favor de si, contra o nada. Contra esse veredicto do Ser não há réplica, pois mesmo a negação do Ser trai um interesse e uma finalidade. Ou seja, o simples fato de que o Ser não seja indiferente a si mesmo torna a diferença de si, em relação ao não-Ser, o valor fundamental de todos os valores; o primeiro 'sim', a princípio. (Ibidem, p.151)

Desta maneira, os próprios seres vivos sensíveis tornam-se afirmadores do ser, uma vez que são fins em si mesmos em sua luta pela sobrevivência a cada momento da ontogênese. Analogamente, a natureza manifesta fins ao dar origem à vida assim como as estruturas de sistemas orgânicos. "[...] na oposição entre o Ser e a morte a afirmação do Ser torna-se enfática." (Ibidem, p.152) Se os seres vivos são fins imanentes por si mesmos, considerá-los como valores é 
dever do homem pois é próprio e exclusivo de seu ser o reconhecimento de tais fins. Ele pode se apropriar deste "bem" presente na natureza e torná-lo sua tarefa, fazendo com que a finalidade, que reivindica sua realização, torne-se para ele um valor. Isto pode apenas ser realizado se o homem fizer também do reconhecido objeto de sua ética alvo de sua vontade.

A "vontade", neste caso, constitui o aspecto afetivo da ética em contraste com sua parte teórica. Jonas faz uma pequena recapitulação da função do sentimento em filosofias morais anteriores:

Os filósofos da moral sempre reconheceram que o sentimento deveria se unir à razão, de modo que o bem objetivo adquirisse poder sobre a nossa vontade; em outras palavras, a moral que supomos que deve se impor às emoções necessita, ela própria, de emoções. [...]. Essa intuição está presente, explícita ou implicitamente, em toda doutrina da virtude, por mais distintas que sejam as formas de definir a emoção em questão. [...] Observamos, além disso, que a maioria dos sentimentos mencionados (mas não todos) são do tipo daqueles inspirados por um objeto (e orientados em direção a ele) que representa um valor supremo, um "bem supremo". Tradicionalmente, esse summum bonum possuía frequentemente a conotação ontológica (um corolário para a ideia de perfeição) de ser algo atemporal, antepondo à nossa mortalidade a sedução da eternidade. O objetivo da ambição ética é, pois, tornar o seu próprio estado semelhante a esse do objeto supremo, "apropriar-se" dele nesse sentido e também fomentar a sua apropriação por parte de outros [...].(Ibidem, p.159)

O sentimento teria em éticas antecedentes a função de ser inspirado por um objeto supremo de caráter atemporal (um "bem") que move o ser humano através do esforço de se assemelhar a esse objeto, sendo o homem, no entanto, limitado por sua realidade temporal e corruptível. Jonas ressalta as similaridades de sua ética em relação às tradicionais, a saber, que "a força impositiva surge como o principal concernido de sua ética um objeto, e a ligação [do agente moral] é com o objeto, seja eterno ou temporal" (Ibidem, p.160). A alternativa proposta por Jonas é também direcionada a um objeto, mas este é perecível, carrega em si o risco da nãoexistência. Demanda, de sua fragilidade, o que Jonas denomina responsabilidade.

Jonas diferencia duas perspectivas principais sobre a responsabilidade. Esta é fundada essencialmente no poder causal, ou seja, na noção de que:

o agente deve responder por seus atos: ele é responsável por suas consequências e responderá por elas, se for o caso. [...] Basta que [...] tenha sido a causa ativa. Mas isso somente se houver um nexo causal estreito com a ação, de maneira que a imputação seja evidente e suas consequências não se percam no imprevisível (Ibidem, p.165)

Em um primeiro olhar, a responsabilidade tem conotação moral ou legal, cujo principal objetivo é a reparação de danos causados por consequências do agente. Neste caso, ela diz 
respeito às decorrências de uma ação quando determinadas após sua execução. A responsabilidade que nos interessa é de outro gênero:

Há outra noção de responsabilidade que não concerne ao cálculo do que foi feito expost facto, mas à determinação do que se tem a fazer; uma noção em virtude da qual eu me sinto responsável, em primeiro lugar, não por minha conduta e suas consequências, mas pelo objeto que reivindica meu agir. [...] $\mathrm{O}$ "porquê" [o alvo dessa responsabilidade] encontra-se fora de mim, mas na esfera de influência do meu poder, ou dele necessitando ou por ele ameaçado. Ao meu poder ele contrapõe o seu direito de existir como é ou poderia ser, e com a vontade moral ele submete o meu poder. (Ibidem, p.167)

Neste caso, a responsabilidade não tem por função a culpabilização com finalidade de reparação de ordem anterior à execução da ação, mas a legitimação da potencia das atividades desempenhadas pelo ator. Objetos concernidos pelo horizonte causal de suas ações são, portanto, dignos de responsabilidade antes mesmo da efetuação dessas ações de maneira que o dever decorre do poder de atuação. As duas formas principais dessa responsabilidade são a política, de cunho estatal e artificial, e a dos pais em relação a seus filhos, imputada pela própria natureza (Ibidem p.173). Jonas reconhece essa última forma como arquetípica para a essência da responsabilidade.

Abre-se caminho para uma "responsabilidade ontológica pela ideia do homem" (Ibidem, p.94), cujo peso não cai sobre os homens futuros por si próprios, mas sobre a ideia de homem que já inclui a presença de sua concretude no mundo. O ser humano é tomado então não como ente substancial fechado em si mesmo, mas como integrante do conjunto total de significação constituído pelos elementos que compõem o mundo. A existência humana deve ser preservada, pois traz consigo um "dever ser", a saber, o dever de sua manutenção enquanto possibilidade de ser o que acaba por implicar também a continuação existencial de seu mundo, imprescindível para essa possibilidade.

O recém-nascido é arquetípico para tal responsabilidade, pois é o que traz esse "dever ser" de modo mais imediato. Ele representa a maneira mais radical da fragilidade presente em todos os seres vivos engajados na conservação de suas próprias existências e sujeitos à degradação temporal. Como diz Jonas, o recém-nascido "reúne em si a força do já existente, que se autorreconhece, e a queixosa impotência do 'não ser ainda'; o incondicional fim em si de todos os viventes e o 'ainda ter de se tornar' das suas próprias capacidades, para garantir esse fim." (Ibidem, p.223) O apelo da existência do recém-nascido deve ser atendido uma vez que lhe falta autossuficiência para a satisfação de suas necessidades básicas. Trata-se aqui de manutenção da possibilidade da responsabilidade, já que, quando completado o desenvolvimento da criança, ela própria será locatária da responsabilidade incontornável oriunda de sua humanidade. Isso, é claro, 
dependerá de que seus progenitores ou responsáveis atendam a este "dever" pelo reconhecimento da finalidade que lhe é de direito, o que ocasiona um "bem" a ser mantido.

Deve haver a coincidência da constatação intelectual desse "bem" e do sentimento de responsabilidade para com a tarefa de sua manutenção no mundo. Jonas reconhece isso como essencial para a ação moral pois, apesar de éticas sustentadas por preceitos racionais, e de seu pleno reconhecimento pelo sujeito ético, sem o sentimento de responsabilidade em relação ao objeto não pode haver ação alguma. A vontade aparece, assim, como condição afetiva necessária para a ação que constitui seu objetivo último. O poder, então, junta-se ao dever e este, por sua vez, enraíza-se no ser.

\section{CONCLUSÃO}

Para Hans Jonas, o atual funcionamento da técnica moderna traz grandes riscos para a existência tanto da natureza como do ser humano. Os resultados de sua aplicação não podem ser previstos com exatidão em virtude de seu descomunal alcance espacial e temporal. Faz-se necessária a elaboração de uma ética para a reivindicação da prudência em relação aos atos do homem. Sua fundamentação metafísica se alicerça na existência de valores objetivos próprios da natureza, embasada em finalidades imanentes em si. Estas carregam o dever de sua realização, que é um apelo para o homem, único vivente dotado de poder para atender ao chamado da responsabilidade. Este deve assim ser incentivado por um "dever ser" próprio dos viventes, que, por sua própria existência e luta pela vida, constantemente reafirmam o Ser. São fins em si mesmos.

É necessário, portanto, garantir a possibilidade das futuras gerações pois, com o advento da técnica moderna, o não-Ser tornou-se possível. Sendo assim, o dever da preservação da própria ideia de ser humano é o primeiro imperativo do qual se derivam todos os outros. Do ser provém uma responsabilidade para com o homem que, por sua vez, carrega consigo a possibilidade futura da própria responsabilidade.

\section{BIBLIOGRAFIA:}

ANDRADE, Ricardo Jardim. A gênese do conhecimento segundo Heidegger. Reflexão, ano VII, n. 23, maio/agosto/1982.

BRANQUINHO, João; MURCHO, Desidério; GOMES, Nelson Gonçalves. Enciclopédia de termos lógico-filosóficos. São Paulo: Martins Fontes, 2006. 
COMTE, Auguste. Curso de filosofia positiva, trad. Coleção “Os Pensadores”, São Paulo: Abril Cultura, 1973.

DARTIGUES, Andre. O que é fenomenologia?. $3^{a}$ ed. Trad. Maria José de Almeida. São Paulo: Moraes, 1992.

HEIDEGGER, Martin. Ser e Tempo. 10ª ed. Petrópolis: Vozes, 2006.

HEIDEGGER, Martin.Ensaios e conferências. 8ª ed. Petrópolis: Vozes, 2002.

HUSSERL, Edmund. La crise des sciences européenes et la phénoménologie transcendentale. trad. Fr. Paris: Gallimard, 1976.

JONAS, Hans. O Princípio Responsabilidade: Ensaio de uma ética para a civilização tecnológica.Rio de Janeiro: Contraponto: Editora PUC-Rio, 2006.

JONAS, Hans. Técnica, medicina e ética: sobre a prática da responsabilidade. Tradução do Grupo de Trabalho Hans Jonas da ANPOF. São Paulo: Paulus, 2013.

SHULL, K.K. Is the Magic Gone? Weber's "Disenchantment of the World" and its Implications for Art in Today's World. Anamesa, New York, v.3, i. 2, p.61, fall. 2005. 